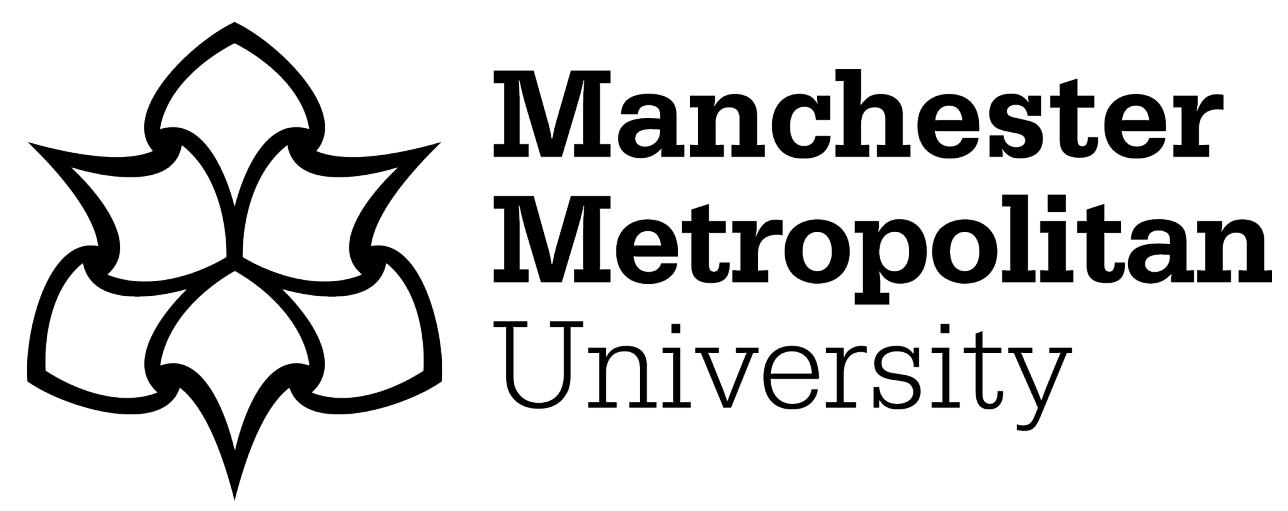

Ang, CS, Tan, JP and Fam, SY (2016) Psychometric Properties of the Training Parenting Style Scale in a Malaysian Sample of Adolescents: Factor Analysis, Internal Consistency, and Measurement Invariance. Journal of Child and Family Studies, 25 (5). pp. 1505-1514. ISSN 1062-1024

Downloaded from: https://e-space.mmu.ac.uk/621310/

Version: Accepted Version

Publisher: Springer

DOI: https://doi.org/10.1007/s10826-015-0333-1

Please cite the published version 


\title{
Psychometric Properties of the Training Parenting Style Scale in a Malaysian Sample of Adolescents: Factor Analysis, Internal Consistency, and Measurement Invariance
}

\author{
Chin-Siang Ang ${ }^{1}$ \\ Jo-Pei Tan ${ }^{2}$ \\ Sin-Yun Fam ${ }^{1}$ \\ ${ }^{1}$ Department of Psychology, Faculty of Social Sciences and \\ Liberal Arts, UCSI University, Jalan Menara Gading, Taman \\ Connaught, 56000 Kuala Lumpur, Malaysia \\ ${ }^{2}$ Department of Social Care and Social Work, Faculty of \\ Health, Psychology and Social Care, Manchester \\ Metropolitan University, Manchester, UK
}

\begin{abstract}
The importance of parenting styles on children's outcomes, including cognitive, social, academic, and values makes this topic a central concern to social researchers and psychologists. However, past research has reported controversial evidence on the relationship between authoritarian parenting and children's outcomes in non-Western cultural contexts. This raises awareness on the implication of cultural differences in parenting styles. As a result, the training parenting style scale (TPSS) was proposed based on the Confucian concept of 'Guan' and 'Chiao Shu.' This scale is allegedly more reflective of the Asian parenting style. The present study examined the psychometric properties and measurement invariance of the Malay version of the TPSS across adolescents' perceived maternal and paternal training and by adolescent gender. Of the 8 items in the original TPSS, confirmatory factor analysis supported 6-item scale with error correlations was the best-fitting model. Internal consistency was also good for the 6-item scale. Furthermore, support for configural, metric, scalar, residual, and structural invariance emerged across adolescents' perceived maternal and paternal training and across adolescent gender. Results of this study supported the psychometric properties of the 6-item TPSS after taking into account several cautiously considered limitations.
\end{abstract}

Keywords: Guan; Parenting Style; Measurement Invariance; Psychometric Properties; Training 


\section{Introduction}

Parenting style is a fascinating scholarly pursuit in the field of child psychology for many years. Darling and Steinberg (1993) defined parenting style as "a constellation of attitudes toward the child that are communicated to the child and that, taken together, create an emotional climate in which the parents' behaviors are expressed" (p. 488). In particular, Baumrind's $(\underline{1966}, \underline{1967})$ conceptualization of parenting into styles which based on the dimension of warmth (i.e. responsiveness) and control (i.e. demandingness), holds a dominant position in the literature (Chao 2001; Padmawidjaja and Chao 2010; Park and Bauer 2002). Warmth refers to actions which intentionally foster psychological autonomy, nurture democratic interactions, and respond to child's needs. In contrast, control refers to actions which purposely promote a sense of familial obligation, supervision from and control of parents over children's behavior. In addition, a mixture of warmth and control produces a tripartite model of parenting styles - the authoritative, authoritarian, and permissive parenting (Baumrind 1966, 1967).

Based on these global typologies of parenting, authoritative parents are characterized by not only high levels of control and warmth but also clear rules and expectation which are often associated with child's autonomy (Rebecca 2006). While, authoritarian parents value child obedience, parental authority and low responsiveness, whereby punishment is often used as a means of child discipline that tend to devalue children's feelings or decision without justifying reasons thereof (Park and Bauer 2002). Permissive parents engage in indulgent style of parenting and typically characterized by low demandingness and high responsiveness in which children are often left to self-regulate their behavior (Rebecca 2006). In addition, superior outcomes of authoritative parenting over authoritarian and permissive parenting style are evident on the development of child cognitive, emotional, social, and behavioral competencies (Onder and Gulay 2009; Simons and Conger 2007; Somayeh and Rozumah $\underline{2009)}$.

The rising interest in parenting styles has generated a range of measurements that based on Baumrind's concept to measure individuals' perception on the quality of parentchild relationship. Some examples include Parenting Style Scale (Simons and Conger, 2007), Measure of Parenting Style (Parker et al. 1997), Parenting Style and Dimensions Questionnaire (Robinson et al. (1995) and Buri's Parenting Authority Questionnaire (1991). While Baumrind's conceptualization of parenting is a useful mean for of describing interaction between parent and children, the application of this concept in Asian contexts remains a point of debate. A growing number of researchers have asserted that the distinction between Western and Asian cultural scripts for parenting not only determine how parenting is defined in these two societies, but also noted the visible distinction in the emphasis on a child's autonomy and self-direction in Western culture, while in contrast, Asian culture perceived that child obedience and conformity are more desirable (Stewart and Bond 2002; Chao and Kaeochinda 2010; Ali and Frederickson 2011).

One of the main issues highlighted in the literature is Asian parents are often dismissed as "controlling" or "lack of warmth" based on Baumrind's conceptualization of parenting. Chao $(1994,1995,2001)$ has challenged the applicability of authoritarian parenting as a valid construct for Asian families as it is equated to controlling-dominating in Western literatures. Although an authoritarian parenting style is considered less preferable in Western culture (i.e. White Middles class American), this style is not always associated with negative outcomes among children in the other cultures such as a collectivist society (Lau and Cheung 1987), 
African-American (Deater-Deckard et al. 1996) and South Asian Canadian families (Ho et al. 2008). In addition, there is evidence that an authoritarian parenting style was the most widely reported style in collective cultures (Chao and Tseng 2002; Padmawidjaja and Chao 2010; Rebecca 2006; Somayeh and Rozumah 2009). More importantly, some studies on Asian American parents also found that authoritarian parenting was positively correlated with child mental well-being, self-development and academic performance (Chao 1994, 1995, 2001). The discrepancy in the literature sheds light that the context of parenting style varies between cultures.

It has been noted that culture variations determine the expectations that parents and children have for parenting (Super and Harkness 1986). Children from different cultural background may assign different connotations to different style of parenting. For instance, physical punishment is an appropriate practice among African-American children, but viewed as a sign of parental rejection by White American children (Deater-Deckard et al. 2005). Similarly, parental control may be seen as a sign of care and concern by African-American children; in contrast, it is often seen as intrusive and dominating by White-American children (Walker-Barnes and Mason 2001). Based on this premise, Chao (1994) has proposed that Chinese parenting style with an emphasis on the Confucian concept of 'Guan' which means love and governing and 'Chiao Shun' which refers to training in culturally appropriate behaviors or morals. Both constructs are thought to be applicable for understanding nonWestern parenting styles as over-arching notions that prescribed parental obligations on nurturing familial unity and maintaining harmonious relationships between children and others (Chao and Tseng 2002; Stewart et al. 1998; Wu and Chao 2005). The Confucian philosophy recognizes that the nature of humans is not naturally good, and perceives that it is the duty of older generation to ensuring children's development (Lam 2007). Indeed, the salience of parent's responsibility is eminently reflected in Confucius' Analects "If you have a child who is a hundred of years old, you have been worrying for at least 99 years" (Lam 2007). More importantly, Asian parents place great emphasis on educational competence and self-discipline of their children (Chao and Sue 1996). Strictness is therefore deeply rooted in the socialization processes between Asian parents and their children to maximize children's achievement potential and teach them appropriate behaviors (Cheah and Rubin 2003). This may explain why Asian parenting has been described as controlling, restrictive, and authoritarian in the Western literature (Padmawidjaja and Chao 2010; Steinberg et al. 1992; Stewart et al. 1998).

The training parenting style scale (TPSS) was constructed based on the concepts of 'Chiao Shun' and 'Guan' that allegedly more reflective of Asian parenting style (Chao 1994; Padmawidjaja and Chao 2010). Stewart and colleagues (2002) has further improved the scale to focus on the aspect of behavior training. Based on samples from three societies (i.e. American, Hong Kong, and Pakistan), the scale shows good acceptability and internal consistency (.68-.78). The findings indicate that the concept of Guan not only reflect Asian indigenous authoritative parenting, but also applicable to other cultures. However, Guan style is the subject of investigation of very few studies (see Stewart et al. 2002; Padmawidjaja and Chao 2010). To the best of our knowledge, the psychometric properties of the TPSS have not been evaluated with Malaysian samples. Neither were we able to locate previous research empirically examines its factor structure across mothers and fathers while gender-based division of child care is keeping debate (Chao and Kaeochinda 2010; Shek 2005). Another important consideration of measuring parenting measures that is lacking in the literature is measurement invariance across gender groups when gender comparisons common in the literature (Lam 2007; Padmawidjaja and Chao 2010). Therefore, the present study aims to address several questions with regard to the psychometric properties of the TPSS among 
school-going adolescents: (1) the reliability and validity of the TPSS; (2) invariance in TPSS scores between mothers and fathers; (3) invariance in TPSS scores of mothers and fathers between gender groups.

\section{Method}

\section{Participants}

The sample comprised of 297 secondary school adolescents of which $49.2 \%$ were males and $50.8 \%$ were females. The age ranged from 12 to16 $(M=13.81, S D=1.27)$. Majority were Malay (56.3\%), followed by Chinese (35.9\%), and Indian (7.8 \%). The average age of fathers and mothers were 48 years $(S D=5.03$, ranging from 34 to 63$)$ and 45 years $(S D=5.10$, ranging from 30 to 62). About sixty-five percent of the participants reported their fathers with lower secondary school educational level and the remaining $35.4 \%$ participants with fathers of upper secondary school educational level. As much as $73.7 \%$ of mothers had completed lower secondary school and the remaining $26.3 \%$ participants reported mothers with upper secondary school educational level.

\section{Procedure}

Data were gathered in secondary school settings and survey administration took place during scheduled class meeting. Participants were informed of the voluntary nature of their participation. Students who agreed to participate were given the survey packets. Each packet contained an explanation letter and the questionnaire. Receipt of returned questionnaire was taken as informed consent. A total of approximately 350 questionnaires were sent out of which 297 were completed and returned. The overall return-rate was about $85 \%$. Prior to data collection, the scale was translated into Malay using Brislin's (1980) method. This was conducted by a native Malay who spoke fluent English, and two faculty members whose native language was Malay whereby independent back-translation was carried out to ensure a correct translation and avoid possible biases. The translated instrument was then subjected to a pilot study among 97 secondary students. No specific problem related to the instrument was reported.

\section{Measures}

\section{Demographic Variables}

Demographic characteristics of the respondents were obtained such as age, gender, and parental information (i.e. age and educational level).

\section{Parental Training Style}

The Training Parenting Style Scale (TPSS; Stewart et al. 2002) was originally created by modifying the Chao's Guan Style Scale (1994) to assess an individual's perception with regards to parents' behaviors when he or she was a young child (specified as 4-8 years of age). Two further items were included in order to attend to an individual's affective experience of parental behavioral control (i.e., organization and discipline). The scale consists of 8 items 
rated on 5-point Likert scale ranging from (1 (strongly disagree) to 5 (strongly agree). Higher scores indicate greater parental training.

\section{Data Analysis}

Descriptive statistics (i.e., mean and standard deviations) and paired sample $t$ test were first carried out in order to provide some preliminary findings of the scale. Confirmatory factor analysis was subsequently conducted using AMOS version 18.0 in order to determine the factor structure of the scale (Byrne 2010). Several fit indices were used to assess model fit: Chi square and its subsequent ratio with degrees of freedom $\left(\chi^{2} / d f\right)$, Comparative Fit Index (CFI), Tucker-Lewis Index (TLI), and Root Mean Square error of approximation (RMSEA) with its $90 \%$ confidence interval (CI) (Hu and Bentler 1999). Criteria for good fit model as proposed by Kline (2004) and $\mathrm{Hu}$ and Bentler (1999) include: the values of $\chi^{2} / d f$ ratio $<3$, a minimum of .95 for CFI and TLI, and RMSEA values $<.06$. Nonetheless, the small sample size of the current study $(\mathrm{N}<400)$ reduced its statistical power for sophisticated analysis (Kim 2005). As a penalty function, we further estimated the standardized factor loadings with a $95 \%$ bootstrap bias-corrected CI (Kim 2005). Following the logic of Kim (2005), CI values of the standardized factor loadings which do not include zero are evidence of significant loadings at the .05 level. In addition, the internal reliability consistency reliability of the scale was determined through the calculation of cronbach's alpha coefficients. A value of .70 and above indicates high reliability (Nunnally and Bernstein 1994).

Analyses of measurement invariance (MI) were carried out next (i.e., configural, metric, scalar, residual, and structure) using multigroup confirmatory factor analysis (MCFA) (Steenkamp and Baumgartner, 1998; Vandenberg and Lance 2000) to examine equivalency of maternal training versus paternal training, as well as males versus females. Specifically, levels of MI were assessed through a sequence of hierarchical nested models by increasing constrained on the baseline model. In step 1, a baseline model (configural invariance) was estimated in which no cross-group equality constraints are imposed. In step 2, test of metric invariance involved specification of factor loadings to be invariant across groups. In step 3 , equality constraints were placed on the factor loadings and item intercepts across groups. In step 4, constraints were imposed for the error variances associated with indicator variables, in addition to the factor loadings and item intercepts to test for residual invariance. In step 5, factor variance was held to equality across groups, in addition factor loadings, item intercepts, and error variances to test for structural invariance. In assessing MI, the most common test is the Chi square difference test $\left(\Delta \chi^{2}\right)$ between nested models (for a full review, see Steenkamp and Baumgartner, 1998; Vandenberg and Lance 2000). Invariance at each level was established if the $\Delta \chi^{2}$ is insignificant at the .05 level between each model and the previous model. The $\Delta \chi^{2}$, however, has limitations in evaluating measurement invariance (Meade et al. 2008), and the delta CFI ( $\triangle$ CFI) between nested models has been recommended (Chen 2007; Cheung and Rensvold 2002). According to Chen (2007) and Cheung and Rensvold (2002), a delta $\mathrm{CFI} \leq .01$ indicates that a model with additional constraints is invariant. Fit statistics were reported with three decimals to further scrutinize the change. Collectively, the Chi square and CFI difference tests between nested models were computed for evidence of invariance. 


\section{Table 1}

Mean, Standard Deviations for Training Parenting Style Scale Items

\begin{tabular}{|c|c|c|c|c|c|c|c|c|c|}
\hline \multirow{2}{*}{$\begin{array}{l}\text { Scale Item } \\
\text { When I was a young child (4-8 years): }\end{array}$} & \multicolumn{4}{|c|}{ Maternal } & \multicolumn{4}{|c|}{ Paternal } & \multirow[b]{2}{*}{ t-value } \\
\hline & Mean & SD & Skewness & Kurtosis & Mean & SD & Skewness & Kurtosis & \\
\hline $\begin{array}{l}\text { Item 1: My father/ mother used physical punishment } \\
\text { when I misbehaved. }\end{array}$ & 2.69 & 1.87 & .56 & -1.26 & 2.63 & 1.87 & .63 & -1.19 & 1.125 \\
\hline Item 2: My father/ mother emphasized self discipline. & 4.77 & 1.42 & -1.25 & .87 & 4.65 & 1.54 & -1.15 & .33 & $2.652 * *$ \\
\hline $\begin{array}{l}\text { Item 3: I was allowed to sleep in my father/ mother's } \\
\text { bed. }\end{array}$ & 3.44 & 2.08 & -.05 & -1.70 & 3.36 & 2.07 & .01 & -1.71 & 1.500 \\
\hline $\begin{array}{l}\text { Item 4: My father/ mother helped me with my studies } \\
\text { as much as his/her education allowed. }\end{array}$ & 4.51 & 1.74 & -1.03 & -.28 & 4.43 & 1.78 & -.92 & -.55 & 1.239 \\
\hline $\begin{array}{l}\text { Item 5: My father/ mother emphasized neatness and } \\
\text { organization. }\end{array}$ & 4.92 & 1.29 & -1.37 & 1.32 & 4.70 & 1.48 & -1.19 & .48 & $3.395^{* *}$ \\
\hline $\begin{array}{l}\text { Item 6: My father/ mother's main concern was his/her } \\
\text { children's needs. }\end{array}$ & 4.97 & 1.30 & -1.48 & 1.73 & 4.89 & 1.40 & -1.40 & 1.20 & 1.623 \\
\hline $\begin{array}{l}\text { Item } 7 \text { : My father/ mother emphasized the importance } \\
\text { of hard work. }\end{array}$ & 5.04 & 1.17 & -1.59 & 2.64 & 4.97 & 1.26 & -1.58 & 2.30 & 1.378 \\
\hline $\begin{array}{l}\text { Item 8: My father/ mother pointed out good behaviours } \\
\text { in others as a model for me. }\end{array}$ & 4.60 & 1.58 & -1.13 & .25 & 4.53 & 1.58 & -1.03 & .02 & 1.095 \\
\hline Total composite score & 34.93 & 6.21 & -.58 & -.88 & 34.15 & 6.76 & -.82 & 1.53 & $3.07 * *$ \\
\hline
\end{tabular}

Note: $\mathrm{SD}=$ Standard deviation, $* * \mathrm{p}<.01$ 


\section{Results}

Results of the descriptive statistics for items and scale scores are as presented in Table $\underline{1}$. It was found that items 'physical punishment' and 'sleep in parents' bed' had lower mean scores and higher level of variability; while items on 'concern children's needs' and 'importance of hard work' reported higher mean scores and lower level of variability. The values of skewness and kurtosis met the assumption of normality (Curran et al. 1996). Paired sample $t$ test revealed significant differences in the scores of mothers $(M=34.93, S D=6.21)$ and fathers $(M=34.15, S D=6.76 ; t(296)=3.07, p<.01)$. Adolescents in this study perceived their mothers put greater emphasis on guan than fathers. In addition, results of $t$ test for each scale item revealed that there were significant differences between maternal guan and paternal guan in terms of self-discipline and neatness. The mean rating of mothers was higher than fathers (see Table 1 ), hence mothers are found to be more concerned about self-discipline and neatness than fathers.

\section{TPSS Factor Structure}

An initial CFA was conducted to assess the degree to which the sample data fit to Stewart et al.'s (2002) proposed factor structure. The 8-item unitary model showed a weak fit by most measures, $X^{2} / d f=2.672, \mathrm{CFI}=.875, \mathrm{TLI}=.825$, RMSEA $=.081(90 \% \mathrm{CI} .064-.096) . \mathrm{A}$ closer inspection found that the standardized loadings of the two items (my father/mother used physical punishment when I misbehaved and I was allowed to sleep in my father/mother's bed) were substantially smaller in magnitude (standardized loadings $<.124$ ). As a result, two problematic items were excluded from the scale. The remaining six items were tested with CFA as a unitary model. This resulted in an improved model fit, $X^{2} / d f=2.501, \mathrm{CFI}=.931$, $\mathrm{TLI}=.885, \mathrm{RMSEA}=.071(90 \% \mathrm{CI} .055-.087)$. Although previous step improved model fit, there was room for improvement. The modification indices suggested that the model would be improved if the errors of item 4 and item 6 were free to correlate. The 6 -item model with error covariances resulted in a reasonably good fit, $X^{2} / d f=2.529, \mathrm{CFI}=.972$, TLI $=.959$, RMSEA $=.072(90 \%$ CI .056-.088) (Table $\underline{2})$. 
Table 2

Summary of Model Fit Statistics

\begin{tabular}{|c|c|c|c|c|}
\hline \multirow[t]{2}{*}{ Models } & \multicolumn{4}{|c|}{ Goodness-of-fit indices } \\
\hline & $X^{2} / d f$ & CFI & TLI & RMSEA (90 \% CI) \\
\hline Recommended value & $\leq 3^{\mathrm{a}}$ & $\geq .95^{\mathrm{b}}$ & $\geq .95^{\mathrm{b}}$ & $\leq .06^{\mathrm{b}}$ \\
\hline \multicolumn{5}{|l|}{ Parental } \\
\hline 8-item model & 2.672 & .875 & .825 & $.081(.064-.096)$ \\
\hline 6-item model (Item 1 and 3 eliminated) & 2.501 & .931 & .885 & $.071(.055-.087)$ \\
\hline $\begin{array}{l}6 \text {-item model with error covariances } \\
\text { between Items } 4 \text { and } 6\end{array}$ & 2.529 & .972 & .959 & $.072(.056-.088)$ \\
\hline \multicolumn{5}{|l|}{ Maternal } \\
\hline $\begin{array}{l}\text { 6-item model with error covariances } \\
\text { between Items } 4 \text { and } 6\end{array}$ & 1.785 & .982 & .966 & $.051(.000-.084)$ \\
\hline \multicolumn{5}{|l|}{ Paternal } \\
\hline $\begin{array}{l}\text { 6-item model with error covariances } \\
\text { between items } 4 \text { and } 6\end{array}$ & 1.796 & .980 & .961 & $.061(.000-.086)$ \\
\hline \multicolumn{5}{|c|}{$\begin{array}{l}X^{2} \text { Chi square statistic, } d f \text { degree of freedom, CFI comparative fit index, TLI Turker-Lewis Index } \\
R M S E A(90 \% C I) \text { root mean square error of approximation }(90 \% \text { confidence interval) }\end{array}$} \\
\hline
\end{tabular}


We also fitted the model separately on maternal training and paternal training. Here again, the model was good fit, maternal: $X^{2} / d f=1.785, \mathrm{CFI}=.982, \mathrm{TLI}=.966, \mathrm{RMSEA}=.051(90 \%$ CI .000-.084); paternal: $X^{2} / d f=1.796$, CFI $=.980$, TLI $=.961$, RMSEA $=.061(90 \%$ CI $.000-.086)$. All items loaded significantly and moderately onto the factor, ranging from .411 to .750 in the maternal model and .336-.812 in the paternal model (see Table $\underline{3}$ ). Subsequently, the examination of the bootstrap CIs of the standardized loadings for both maternal and paternal models revealed that zero was not contained in each $95 \%$ CIs, this seem to indicate that the maximum likelihood yields significance in the factor loadings after taking into account non-normality and small sample size.

Table 3

Standardized factor loadings for the 6-item training parenting style scale

\begin{tabular}{lcccc}
\hline \multirow{2}{*}{ Items } & \multicolumn{2}{c}{ Standardized factor loadings $\mathbf{( 9 5} \%$ bootstrap CI) } & \multicolumn{2}{c}{$\mathbf{R}^{\mathbf{2}}$} \\
\cline { 2 - 5 } & Maternal & Paternal & Maternal & Paternal \\
\hline Self-discipline & $.467(.309-.608)$ & $.527(.381-.642)$ & .22 & .28 \\
Helping in study & $.411(.260-.543)$ & $.622(.521-.704)$ & .17 & .39 \\
Neatness and organization & $.750(.611-.854)$ & $.812(.710-.905)$ & .56 & .66 \\
Concern children's needs & $.513(.341-.652)$ & $.699(.555-.812)$ & .26 & .49 \\
Importance of hard work & $.725(.613-.827)$ & $.648(.523-.752)$ & .53 & .42 \\
Taking others as a model & $.475(.330-.615)$ & $.336(.146-.424)$ & .23 & .09 \\
\hline
\end{tabular}

$95 \%$ Bootstrap CI $95 \%$ bootstrap confidence interval, $\mathrm{R}^{2}=$ coefficient of determination

$\mathrm{N}=1000$ bootstrapping resamples 
Additionally, the internal reliability of the 6-item for paternal training and maternal training, as measured by Cronbach's alpha coefficients, were displayed acceptable reliability $(\alpha>.70)$, see Table $\underline{4}$. This indicates that item responses are highly correlated. Item-total correlations ranged from .32 to .51 in the maternal model, and .26-.52 in the paternal model, and there were no items for which removal would have resulted in improved reliability. Therefore, the model, depicted graphically in Fig. 1 , served as the baseline model whereby it was tested for its equivalence across maternal training and paternal training, as well as male and female adolescents.

\section{Table 4}

\section{Internal consistency for the training parenting style scale}

\begin{tabular}{|c|c|c|c|c|}
\hline & Item retained & Item dropped & ITC & $\begin{array}{c}\text { Alpha if item } \\
\text { deleted }\end{array}$ \\
\hline & Self-discipline & & .37 & .48 \\
\hline & Helping in study & & .36 & .48 \\
\hline & Neatness and organization & & .46 & .46 \\
\hline \multirow[t]{5}{*}{ Maternal } & Concern children's needs & & .45 & .46 \\
\hline & Importance of hard work & & .51 & .45 \\
\hline & Taking others as a model & & .32 & .50 \\
\hline & & Physical punishment & -.02 & .62 \\
\hline & & Sleep on parent's bed & -.01 & .64 \\
\hline \multirow[t]{4}{*}{ alpha } & $.55(8$ items $)$ & .72 (6 items) & & \\
\hline & Self-discipline & & .47 & .52 \\
\hline & Helping in study & & .49 & .50 \\
\hline & Neatness and organization & & .52 & .51 \\
\hline \multirow[t]{5}{*}{ Paternal } & Concern children's needs & & .49 & .52 \\
\hline & Importance of hard work & & .49 & .53 \\
\hline & Taking others as a model & & .26 & .58 \\
\hline & & Physical punishment & .00 & .67 \\
\hline & & Sleep on parent's bed & 01 & .68 \\
\hline alpha & $.60(8$ items $)$ & .75 (6 items) & & \\
\hline
\end{tabular}




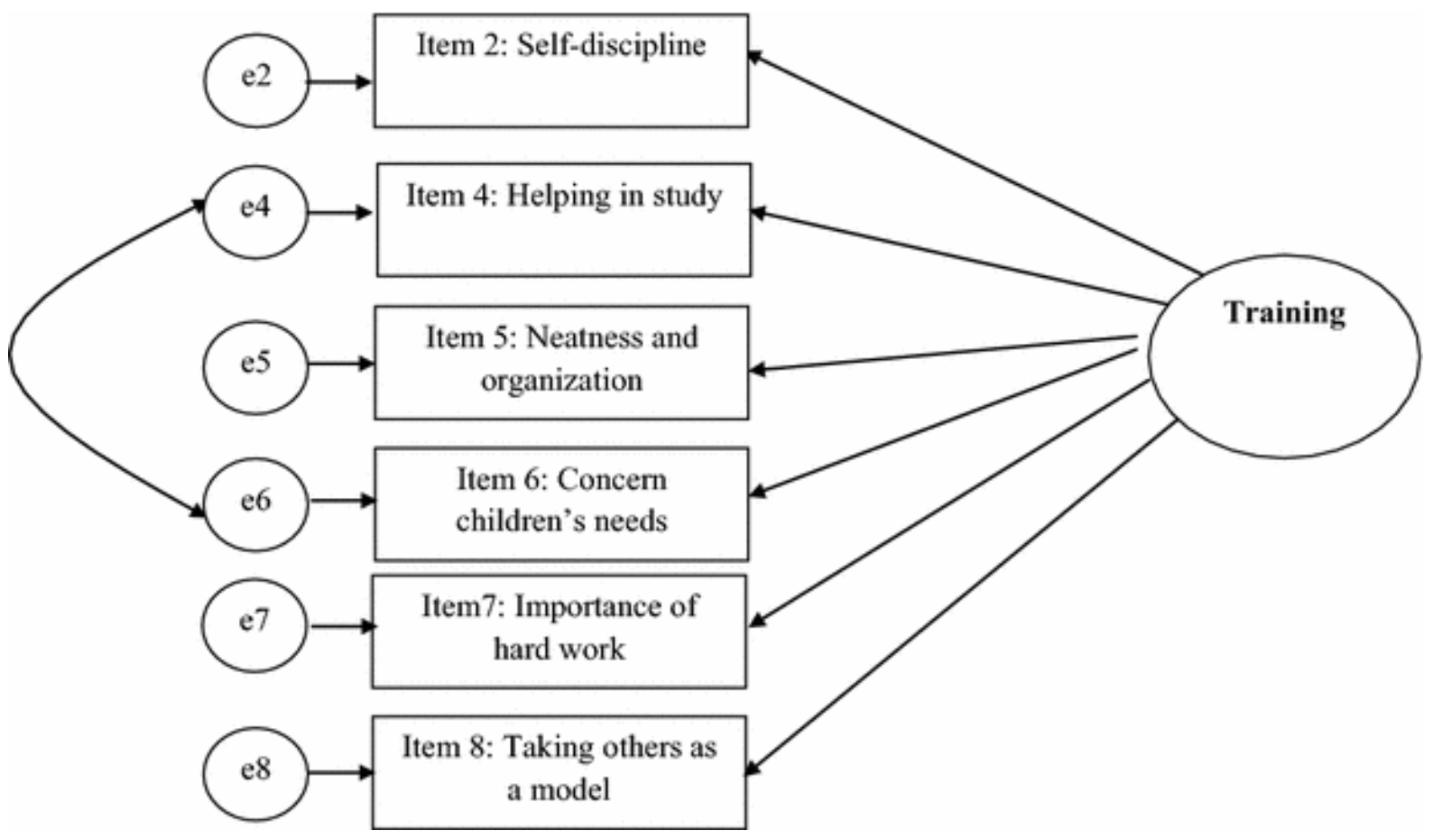

Fig. 1 6-Item TPSS Model with error covariances

\section{Testing for Invariance Across Maternal Training and Paternal Training}

As noted earlier, tests of measurement invariance include a set of hierarchically structured levels in which equality constraints were imposed on particular parameters in the baseline model. As reported in Table $\underline{5}$, the baseline model (Model 1) revealed an adequate fit to the data and this indicates full configure invariance. Compared to the Model 1, the Model 2 yielded a non-significant Chi square change and a small change in CFI, thus supported full metric invariance. The full scalar invariance (Model 3) was also obtained in comparison to the metric invariance model. Thereafter, the fit of the residual invariance model (Model 4) was still acceptable and did not differ significantly from the scalar model and this indicates full residual invariance. In accordance to the evidence of full residual invariance, we proceeded to test for the structural invariance (Model 5). This model produced reasonable fit indices and did not differ significantly from the previous model. These results satisfied the requirement of full structural invariance. 
Table 5

Invariance constraints for the training parenting style scale across maternal training and paternal training

\begin{tabular}{|c|c|c|c|c|c|c|c|c|}
\hline Model & $X^{2} / d f$ & CFI & TLI & $\begin{array}{c}\text { RMSEA } \\
\text { (90 \% CI) }\end{array}$ & $\begin{array}{c}\text { Model } \\
\text { comparison }\end{array}$ & $\Delta X^{2}$ & $\Delta d f$ & $\Delta \mathrm{CFI}$ \\
\hline $\begin{array}{l}\text { Recommend } \\
\text { ed value }\end{array}$ & $\leq 3^{\mathrm{a}}$ & $\geq .95^{\mathrm{b}}$ & $\geq .95^{\mathrm{b}}$ & $\leq .06^{\mathrm{b}}$ & & $p>.05^{c}$ & - & $\begin{array}{l}\leq \\
.010^{d}\end{array}$ \\
\hline $\begin{array}{l}\text { Model 1: } \\
\text { Full } \\
\text { configural } \\
\text { invariance }\end{array}$ & 2.529 & .972 & .959 & $\begin{array}{l}.052(.036- \\
.068)\end{array}$ & - & - & - & - \\
\hline $\begin{array}{l}\text { Model 2: } \\
\text { Full metric } \\
\text { invariance }\end{array}$ & 2.577 & .968 & .958 & $\begin{array}{l}.053(.038- \\
.069)\end{array}$ & 2 versus 1 & 12.023 & 5 & .004 \\
\hline $\begin{array}{l}\text { Model 3: } \\
\text { Full scalar } \\
\text { invariance }\end{array}$ & 2.537 & .965 & .959 & $\begin{array}{l}.052(.037- \\
.067)\end{array}$ & 3 versus 2 & 11.265 & 6 & .003 \\
\hline $\begin{array}{l}\text { Model 4: } \\
\text { Full residual } \\
\text { invariance }\end{array}$ & 2.513 & .962 & .960 & $\begin{array}{l}.052(.038- \\
.066)\end{array}$ & 4 versus 3 & 11.731 & 6 & .003 \\
\hline $\begin{array}{l}\text { Model 5: } \\
\text { Full } \\
\text { structural } \\
\text { invariance }\end{array}$ & 2.658 & .958 & .956 & $\begin{array}{l}.055(.041- \\
.069)\end{array}$ & 5 versus 4 & 10.648 & 1 & .004 \\
\hline
\end{tabular}

Note: $X^{2}=$ Chi-square; $\mathrm{df}=$ degree of freedom, $\mathrm{CFI}=$ comparison fit index; $\mathrm{TLI}=$ Turker-Lewis Index, RMSEA= mean square error of approximation

a. Kline (1998)

b. Hu \& Bentler (1999)

*Freed intercepts for item 'My mother helped me with my studies as much as his/her education allowed"

\section{Tests of Invariance Between Males and Females}

\section{Maternal Training}

As reported in Table $\underline{6}$, results of multi-group CFA revealed that full configural invariance, full metric invariance, full residual invariance, and full structural invariance were well established. However, the results provided evidence against full scalar invariance. Partial scalar invariance was established by relaxing constraints on the intercept of the item 'My mother helped me with my studies as much as her education allowed.' 
Table 6

Invariance constraints for the training parenting style scale across adolescent gender

\begin{tabular}{|c|c|c|c|c|c|c|c|c|}
\hline Model & $X^{2} / d f$ & CFI & TLI & $\begin{array}{c}\text { RMSEA (90 } \\
\text { CI) } \\
\end{array}$ & $\begin{array}{c}\text { Model } \\
\text { comparison }\end{array}$ & $\Delta X^{2}$ & $\Delta d f$ & $\Delta \mathrm{CFI}$ \\
\hline $\begin{array}{l}\text { Recommended } \\
\text { value }\end{array}$ & $\leq 3^{\mathrm{a}}$ & $\geq .95^{\mathrm{b}}$ & $\geq .95^{b}$ & $\leq .06^{b}$ & & $p>.05^{c}$ & - & $\leq .010^{\mathrm{d}}$ \\
\hline \multicolumn{9}{|l|}{ Maternal } \\
\hline $\begin{array}{l}\text { Model 1: Full } \\
\text { configural } \\
\text { invariance }\end{array}$ & 1.319 & .985 & .972 & $\begin{array}{l}.033(.000- \\
.067)\end{array}$ & - & - & - & - \\
\hline $\begin{array}{l}\text { Model 2: Full } \\
\text { metric } \\
\text { invariance }\end{array}$ & 1.312 & .975 & .969 & $\begin{array}{l}.032(.000- \\
.063)\end{array}$ & 2 versus 1 & 6.436 & 5 & .010 \\
\hline $\begin{array}{l}\text { Model 3: Full } \\
\text { scalar } \\
\text { invariance }\end{array}$ & 1.501 & .961 & .956 & $\begin{array}{l}.041(.006- \\
.066)\end{array}$ & 3 versus 2 & $12.966^{*}$ & 6 & .014 \\
\hline $\begin{array}{l}\text { Model 4: } \\
\text { Partial scalar } \\
\text { invariance* }\end{array}$ & 1.454 & .966 & .960 & $\begin{array}{l}.039(.000- \\
.065)\end{array}$ & 4 versus 2 & 10.255 & 5 & .009 \\
\hline $\begin{array}{l}\text { Model 5: Full } \\
\text { residual } \\
\text { invariance }\end{array}$ & 1.489 & .959 & .953 & $\begin{array}{l}.041(.011- \\
.063)\end{array}$ & 5 versus 4 & 11.343 & 7 & .007 \\
\hline $\begin{array}{l}\text { Model 6: Full } \\
\text { structural } \\
\text { invariance }\end{array}$ & 1.516 & .955 & .949 & $\begin{array}{l}.042(.014- \\
.064)\end{array}$ & 6 versus 5 & 2.408 & 1 & .004 \\
\hline \multicolumn{9}{|l|}{ Paternal } \\
\hline $\begin{array}{l}\text { Model 1: Full } \\
\text { configural } \\
\text { invariance }\end{array}$ & 1.744 & .984 & .974 & $\begin{array}{l}.050(.015- \\
.081)\end{array}$ & - & - & - & - \\
\hline $\begin{array}{l}\text { Model 2: Full } \\
\text { metric } \\
\text { invariance }\end{array}$ & 1.374 & .980 & .972 & $\begin{array}{l}.036(.000- \\
.065)\end{array}$ & 2 versus 1 & .947 & 5 & .004 \\
\hline $\begin{array}{l}\text { Model 3: Full } \\
\text { scalar } \\
\text { invariance }\end{array}$ & 1.356 & .976 & .973 & $\begin{array}{l}.035(.000- \\
.061)\end{array}$ & 3 versus 2 & 7.767 & 6 & .004 \\
\hline $\begin{array}{l}\text { Model 4: Full } \\
\text { residual } \\
\text { invariance }\end{array}$ & 1.420 & .971 & .967 & $\begin{array}{l}.036(.000- \\
.059)\end{array}$ & 4 versus 3 & 10.234 & 6 & .005 \\
\hline $\begin{array}{l}\text { Model 5: Full } \\
\text { structural } \\
\text { invariance }\end{array}$ & 1.389 & .969 & .965 & $\begin{array}{l}.038(.000- \\
.061)\end{array}$ & 5 versus 4 & .376 & 1 & .002 \\
\hline
\end{tabular}


$X^{2}=$ Chi square statistic, $d f$ degree of freedom, CFI comparative fit index; TLI Turker-Lewis index, RMSEA

$(90 \% C I)$ root mean square error of approximation ( $90 \%$ confidence interval), $\Delta X^{2}$ difference of the Chi square values, $\Delta d f$ difference of the degrees of freedom, $\Delta$ CFI delta comparative fit index

${ }^{\mathrm{a}} \mathrm{K}$ line $(\underline{2004})$

${ }^{\mathrm{b}} \mathrm{Hu}$ and Bentler (1999)

'Steenkamp and Baumgartner (1998)

${ }^{\mathrm{d}}$ Chen (2007)

$* p<.05$

\section{Paternal Training}

CFA models were then run separately by respondents' genders using the same methods described above to examine MI for the paternal model. Results of the multi-group CFA (refer to Table 6 ) provided evidence for full configural invariance (Model 1), full metric invariance (Model 2), full scalar invariance (Model 3), full residual invariance (Model 4) and full structural invariance (Model 5) by means of the changes in $X^{2}$ and CFI.

\section{Discussion}

The present study had three goals. First, this study examined the psychometric properties of the Malay version of TPSS in a sample of school-going adolescents. Second, this study tested the measurement invariance of maternal training and paternal training. Third, this study investigated the measurement invariance of maternal training and paternal training across adolescent gender. Preliminary analysis showed that adolescents in this study reported mothers scored higher on self-discipline, neatness, and organizations than fathers. The findings are consistent with past findings that the respondents perceived stronger guan among mothers than fathers (Shek 2005; Stewart et al. 2002). According to Stewart et al. (2002), countries with Confucian cultures highly valued family teaching or "jia jiao" in order to nurture children to show good and proper behaviors. It is generally agreed that fathers are main earners in a family who held more accountable for supporting the daily needs of other family members. In contrast, mothers are often perceived as primary caregivers who occupy a more privileged position in the upbringing of children. In another similar, mothers were also found to be more engaging than fathers to fulfill the responsibility of caregiving and nurturing their children (Shek 2005). Therefore, fathers may not always be overly involved in monitoring and guiding children in developing acceptable behaviors and the responsibility of child training is often passed on to mothers.

Using CFA, it was shown that the original 8-item model provided a poor fit in the parental model. Removal of items 1 and 3 improved model fit and internal consistency noticeably. In support of Stewart et al. (2002), these two items (use of physical punishment and sleeping in father's/mother's bed) had particularly weak loadings in the maternal model and paternal model separately. In their studies which have explored the factor structure of the TPSS in Hong Kong, Pakistan, and United States populations using principal components extraction concluded that two items from the scale should be discarded from the scale. After exclusion, 6-item factor loadings ranged from .35 to .75 in Hong Kong, .34-.81 in Pakistan, and .44-.74 in the United States samples. Further, the 6-item TPSS demonstrate good internal 
consistency for maternal training and paternal training separately. These results are comparable to the previous studies (Stewart et al. 1998), which suggests that item-total correlations for these six items were uniformly high across maternal training and paternal training (ranging from .35 to .60). Taken together, the 6-item TPSS is a valid and reliable measure of parenting style with adequate psychometric properties and internal consistency.

Error covariances between items 4 (helping in studying) and 6 (concern on children's needs) were also found, providing support for content overlapping between the items (Byrne 2010). To some extent, the error covariances reported in this study correspond with the culturally-resonant stereotypes. This finding is similar to those found by Rebecca (2006) and Somayeh and Rozumah (2009), demonstrating that academic success is highly valued in collectivistic societies and is seen as a pathway toward securing a promising future for children. As a result, parents are held socially accountable for training their child's education and parental involvement in child's education has been a symbolic affirmation as good fathers or mothers who always care their children's needs.

In addition to the validity and reliability of the measure, we turn now to evaluating invariance between maternal training and paternal training. Following Vandenberg and Lance (2000) and Chen (2007) approach, we tested whether all or some of the factor structures, factor loadings, item intercepts, error variances, and factor variances are equal between maternal training and paternal training. The invariance tests demonstrated that there were no differences between mothers and fathers at the configural, metric, scalar, residual, and structural levels. The findings imply mothers and fathers should no longer be regarded as opposites though they often bring different strengths and styles to their parenting roles and each is necessary for healthy child-rearing. Gender invariance in the paternal training and maternal training models were also examined to test whether all or some of the factor structures, factor loadings, item intercepts, error variances, and factor variances are equal between gender (Chen 2007; Vandenberg and Lance 2000). In general, maternal training items showed full configural, full metric, full residual, and full structural invariance. However, the items failed to show full scalar invariance, and thus, we relaxed an item resulted in partial scalar invariance in the model. Further, there was virtually no difference in the paternal training by gender. These findings suggest that full invariances were detected in all five levels of measurement equivalence between male and female adolescents in the paternal model. Overall, there was fairly good support for parental invariance and gender invariance for the TPSS. These tests confirmed that the 6-item model of TPSS is modestly well-fitted across mothers and fathers, as well as males and females. Given such findings, it is now generally accepted that TPSS is equally applicable and relevant for understand the mothers' training and fathers' training of male and female adolescents when they were in childhood.

However, several limitations of the study deserve comment. First, the sample was predominantly Malay, recruited from secondary schools, and drawn from a limited geographical region of Malaysia. While this distribution is comparable to the general Malaysian population, generalizability of these findings to other populations awaits further research. Further research using larger sample sizes in different geographical localities is necessary to increase the power of the psychometric attributes investigation. Second, the nature of cross-sectional design limits the exploration of stability of the scale for the present study. Longitudinal research is needed to evaluate the robustness of the TPSS over time. In addition, this study relied exclusively on self-reported measure to assessing the validity of the scale. This may pose internal biases and shared method variance. Future research that goes beyond self-reported is needed. We acknowledge, however, that this study does not 
specifically seek to address all aspects of validity such as criterion-related validity. In relation to the issue, we suggest further research to continue the TPSS validation process to provide additional evidence of the psychometric properties of the TPSS.

Within these limitations, our findings constitute a significant research gap on the validation of TPSS. This is the first validation of the TPSS in Malay, a previously unstudied language. It is also the first validation of the scale to disentangle the invariance of maternal training and paternal training, as well as males and females in TPSS scores. Moreover, research on training or guan style has been minimal with parenting research attention focused primarily on Baumrind's parenting styles. Given that the parenting styles' findings are intriguing in Asia, the TPPS is a viable alternative. It is evident from the present study not only serve as useful reference for exploring the concept of guan, it is also provides confidence for parenting researchers on the psychometric qualities of this construct. In conclusion, the present work shows that it is possible to reliably and validly measure the parenting style in adolescents by use of the 6-item TPSS.

\section{Reference}

Ali, S., \& Frederickson, N. (2011). The parenting dimensions of British Pakistani and White mothers of primary school children. Infant and Child Development, 20(3), 313-329. doi: $\underline{10.1002 / \text { icd.696. }}$.

Baumrind, D. (1966). Effects of authoritative parental control on child behavior. Child Development, 37(4), 887-907. doi: 10.2307/1126611.

Baumrind, D. (1967). Child care practices anteceding three patterns of preschool behavior. Genetic Psychology Monographs, 75(1), 43-48.

Brislin, R. W. (1980). Translation and content analysis of oral and written material. In H. C. Triandis \& J. W. Berry (Eds.), Handbook of cross-cultural psychology (Vol. 1, pp. 389-444). Boston: Allyn \& Bacon. Buri, J. R. (1991). Parental authority questionnaire. Journal of Personality and Social Assessment, 57, 110-119. doi: $\underline{10.1207 / \mathrm{s} 15327752 \mathrm{jpa} 5701 \quad 13 .}$.

Byrne, B. M. (2010). Structural equation modeling with AMOS: Basic concepts, applications, and programming (2nd ed.). New York: Taylor and Francis Group.

Chao, R. K. (1994). Beyond parental control and authoritarian parenting style: Understanding Chinese parenting through the culture notion of training. Child Development, 65(4), 1111-1119. doi: 10.1111/1467-8624.ep7252822.

Chao, R. K. (1995). Chinese and European American cultural models of the self reflected in mothers' childrearing beliefs. Ethos, 23(3), 328-354.

doi: $10.1525 /$ eth.1995.23.3.02a00030. 
Chao, R. K. (2001). Extending research on the consequences of parenting style for Chinese Americans and European Americans. Child Development, 72(6), 1832-1843. doi: $\underline{10.1111 / 1467-8624.00381}$.

Chao, R. K., \& Kaeochinda, K. F. (2010). Parental sacrifice and acceptance as distinct dimensions of parental support among Chinese and Filipino American adolescents. In S. T. Russell, L. J. Crockett, \& R. K. Chao (Eds.), Asian American parenting and parent-adolescent relationships, Advancing responsible adolescent development (pp. 61-77). New York: Springer.

Chao, R. K., \& Sue, S. (1996). Chinese parental influences and their children's school success: A paradox in the literature on parenting style. In S. Lau (Ed.), Growing up the Chinese way: Chinese child and adolescent development (pp. 93-120). Hong Kong: Chinese University Press.

Chao, R. K., \& Tseng, V. (2002). Parenting of Asians. In M. H. Bornstein (Ed.), Handbook of Parenting: Vol. 4. Social Conditions and Applied Parenting (2nd ed., pp. 59-93). Mahwah: Lawrence Erlbaum Associates.

Cheah, C. S., \& Rubin, K. (2003). European American and Mainland Chinese mothers' socialization beliefs regarding preschoolers' social skills. Parenting Science and Practice, 3, 1-22. doi: 10.1207/S15327922PAR0301 01.

Chen, F. F. (2007). Sensitivity of goodness of fit indexes to lack of measurement invariance. Structural Equation Modeling, 14(3), 464-504. doi: 10.1080/10705510701301834.

Cheung, G. W., \& Rensvold, R. B. (2002). Evaluating goodness-of-fit indexes for testing measurement invariance. Structural Equation Modeling, 9(2), 233-255. doi: 10.1207/S15328007SEM0902_5.

Curran, P. J., West, S. G., \& Finch, G. F. (1996). The robustness of test statistics to nonnormality and specification error in confirmatory factor analysis. Psychological Methods, 1(1), 16-29. doi: 10.1037/1082-989X.1.1.16.

Darling, N., \& Steinberg, L. (1993). Parenting style as context: An integrative model. Psychological Bulletin, 113, 487-496.

Deater-Deckard, K., Dodge, K. A., Bates, J. E., \& Pettit, G. S. (1996). Physical discipline among African American and European American mothers: Links to children's externalizing behaviors. Developmental Psychology, 32(6), 1065-1072. doi: $10.1037 / 0012-1649.32 .6 .1065$.

Deater-Deckard, K., Dodge, K. A., \& Sorbring, E. (2005). Cultural differences in the effects of physical punishment. In M. Rutter \& M. Tienda (Eds.), Ethnicity and causal mechanisms (pp. 204-226). Cambridge: Cambridge University Press.

Ho, C., Bluestein, D. N., \& Jenkins, J. (2008). Cultural differences in the relationship between parenting and children's behavior. Developmental Psychology, 44(2), 507522. doi: 10.1037/0012-1649.44.2.507. 
Hu, L. T., \& Bentler, P. M. (1999). Cutoff criteria for fit indexes in covariance structure analysis: Conventional criteria versus new alternatives. Structural Equation Modeling, 6(1), 1-55. doi: 10.1080/10705519909540118.

Kim, K. H. (2005). The relation among fit indexes, power, and sample size in structural equation modeling. Structural Equation Modeling, 12(3), 368-390. doi: $10.1207 / \mathrm{s} 15328007 \mathrm{sem} 12032$.

Kline, R. B. (2004). Principles and practice of structural equation modeling (2nd ed.). New York: Guildford.

Lam, C. M. (2007). Not grown up forever: A Chinese Conception of Adolescent Development. New York: Nova Science Publishers, Incorporation.

Lau, S., \& Cheung, P. C. (1987). Relations between Chinese adolescents' perception of parental control and organization and their perception of parental warmth. Developmental Psychology, 23(5), 726-729. doi: 10.1037/0012-1649.23.5.726.

Meade, A. W., Johnson, E. C., \& Braddy, P. W. (2008). Power and sensitivity of alternative fit indices in test of measurement invariance. Journal of Applied Psychology, 93(3), 568-592. doi: 10.1037/0021-9010.93.3.568.

Nunnally, J. C., \& Bernstein, I. H. (1994). Psychometric theory (3rd ed.). New York: McGraw-Hill.

Onder, A., \& Gulay, H. (2009). Reliability and validity of parenting styles \& dimensions questionnaire. Procedia Social and Behavioral Sciences, 1, 508-514. doi: 10.1016/j.sbspro.2009.01.092.

Padmawidjaja, I. A., \& Chao, R. K. (2010). Parental beliefs and their relation to the parental practices of Immigrant Chinese Americans and European Americans. In S. T. Russell, L. J. Crockett, \& R. K. Chao (Eds.), Asian American parenting and parent-adolescent relationships: Advancing responsible adolescent development (pp. 37-60). New York: Springer.

Park, H., \& Bauer, S. (2002). Parenting practices, ethnicity, socioeconomic status and academic achievement in adolescents. School Psychology International, 23(4), 386396. doi: $\underline{10.1177 / 0143034302234002}$.

Parker, G., Roussos, J., Hadzi-Pavlovic, D., Mitchell, P., Wilhelm, K., \& Austin, M. P. (1997). The development of a refined measure of dysfunctional parenting and assessment of its relevance in patients with affective disorders. Psychological Medicine, 27(5), 1193-1203. doi: 10.1017/S003329179700545X.

Rebecca, P. A. (2006). Effects of parenting style on personal and social variables for Asian, adolescents. American Journal of Orthopsychiatry, 76(4), 503-511. doi: $\underline{10.1037 / 0002-9432.76 .4 .503}$. 
Robinson, C. C., Mandleco, B., Olsen, S. F., \& Hart, C. H. (1995). Authoritative, authoritarian, and permissive parenting practices: Development of a new measure. Psychological Reports, 77(3), 819-830. doi: 10.2466/pr0.1995.77.3.819.

Shek, D. T. L. (2005). Perceived parental control and parent-child relational qualities in Chinese adolescents in Hong Kong. Sex Roles, 53(9-10), 635-646. doi: $10.1007 / \mathrm{s} 11199-005-7730-7$.

Simons, G. L., \& Conger, R. D. (2007). Linking father-mother differences in parenting to a typology of parenting style and adolescent outcomes. Journal of Family Issue, 28(2), 212-241. doi: 10.1177/0192513X06294593.

Somayeh, K., \& Rozumah, B. (2009). Parenting style in a collectivist culture of Malaysia. European Journal of Social Science, 10(1), 66-73.

Steenkamp, J.-B. E. M., \& Baumgartner, H. (1998). Assessing measurement invariance in cross-national consumer research. Journal of Consumer Research, 25(1), 78-107.

Steinberg, L., Dornbusch, S. M., \& Brown, B. (1992). Ethnic differences in adolescent achievement in ecological perspective. American Psychologist, 47(6), 723-729. doi: $10.1037 / 0003-066 X .47 .6 .723$.

Stewart, S. M., \& Bond, M. H. (2002). A critical look at parenting research from the mainstream: Problems uncovered while adapting Western research to non-western cultures. British Journal of Developmental Psychology, 20(3), 379-392. doi: $10.1348 / 026151002320620389$.

Stewart, S. M., Bond, M. H., Kennard, B. D., Ho, L. M., \& Zaman, R. M. (2002). Does the Chinese construct of guan export to the West? International Journal of Psychology, 37(2), 74-82. doi: 10.1080/00207590143000162.

Stewart, S. M., Rao, N., Bond, M. H., McBride-Chang, C., Fielding, R., \& Kennard, B. D. (1998). Chinese dimensions of parenting: Broadening Western predictors and outcomes. International Journal of Psychology, 33(5), 345-358. doi: $10.1080 / 002075998400231$.

Super, C. M., \& Harkness, S. (1986). The developmental niche: A conceptualization at the interface of child and culture. International Journal of Behavioral Development, 9(4), 545-569. doi: 10.1177/016502548600900409.

Vandenberg, R. J., \& Lance, C. E. (2000). A review and synthesis of the measurement invariance literature: Suggestions, practices, and recommendations for organizational research. Organizational Research Methods, 3(1), 4-70. doi: $10.1177 / 109442810031002$.

Walker-Barnes, C. J., \& Mason, C. A. (2001). Ethnic differences in the effect of parenting upon gang involvement and gang delinquency: A longitudinal HLM perspective. Child Development, 72(6), 1814-1831. doi: 10.1111/1467-8624.00380. 
Wu, C., \& Chao, R. K. (2005). Intergenerational cultural conflicts in norms of parental warmth among Chinese American immigrants. International Journal of Behavioral Development, 29(6), 516-523. doi: 10.1080/01650250500147444. 